\title{
Exploring Novel Technologies to Enhance Food Safety Training and Research Opportunities
}

\author{
Joseph E. B. Baldwin ${ }^{1 *}$ and Ellen W. Evans ${ }^{2}$ \\ 'Perceptual Experience Laboratory, Cardiff School of Art and Design, Cardiff Metropolitan University, Western Ave., Llandaff, Cardiff, Wales CF5 2YB \\ 2ZERO2FIVE Food Industry Centre, Cardiff Metropolitan University, Western Ave., Llandaff, Cardiff, Wales CF5 2YB
}

\section{SUMMARY}

In food safety research focused on consumers in the domestic setting or on food handlers in the industry, technologic advancements have improved the rigor of research findings, reduced research biases, simplified data collection methods, and enhanced the delivery of food safety education and training. Use of online surveys can save time over use of paper-based surveys because data entry is eliminated and data analysis can be simplified (44). The cost, availability, and portability of surveillance equipment has enabled covert observational research on consumer food safety practices in domestic environments $(34,81)$ and on food handlers in industry settings $(20,36,37)$.

New technologies also afford many new opportunities to interact with target audiences. These evolving technologies are changing the way in which computer screens are used and could allow the food industry and researchers to create new and stimulating experiences that benefit study areas such as food safety behaviors, cognition, and training.

Advancements in technology have allowed food safety researchers and user-centered design researchers to join forces to explore novel techniques that can be utilized to enhance food safety training and research opportunities. The aim of this article is to explore alternative approaches such as biometric and virtual or augmented reality technologies that can be utilized by food safety researchers to enhance understanding of food safety practices, increase industry insight into food safety behaviors, and present opportunities to optimize food safety education prospects. This article provides an overview of several physiological and psychological technologies that can be used in simulated environments, with applied user testing, in product development, and in behavioral analysis research.

\section{OVERVIEW}

The terms virtual reality (VR) and augmented reality (AR) are often misunderstood. Here, we describe the main characteristics of and differences between these technologies in simulated task environments and with eye tracking and biometric techniques and consider how we can utilize these approaches to benefit food safety research, training, and education in the future.

\section{VR technology}

VR technology is generally used to immerse users in a computer-generated environment so that they can feel present in virtual worlds away from the body's physical location. Simulated environments are largely experienced through a head-mounted display with stereoscopic binocular technology that projects independent images onto each eye, producing a sense of depth based on human binocular disparity (two-eye view) (41).

The earliest known example of VR technology, the Sensorama, was developed in the late 1950s (52). This mechanical system provided an immersive video experience that was used to train individuals without subjecting them to possible hazards of particular situations (51). Significant advancements have been made to VR technology and head-mounted displays, such as producing the sensation of peripheral vision and the viewer's changed orientation within an environment (100) and the ability to navigate simulations with stereoscopic vision and access embedded information in the form of anchored hypermedia links $(16,17,85)$.

Within VR environments, presence and immersion are recognized as highly necessary for user satisfaction (22). Immersion is determined by the technical provision of the VR technology, and presence is the psychological response to the VR environment, the feeling of "being there," obtained through the external sensory information $(5,64,95)$. For a VR experience to feel realistic, user presence is optimized by providing a first-person point of view, which is the way in which humans judge sense of depth and experience being engaged in the world (48). In video games, attempts to improve immersive depth have included the representation of the person playing the game from a first-person perspective.

\section{VR application for food safety training}

VR technology has been developed and used within military, commercial, health care, and research applications to simulate the sensations of an actual experience in an individual undergoing real-life training (52). VR flight simulators have been used to improve the decision making and performance of combat pilots $(29,56)$, and headmounted display technology has enabled architects to 
immerse clients in designs from a first-person point of view, gaining improved spatial impressions and customer experience (15).

The popularity of VR headsets for entertainment and gaming has reduced their cost, which could in turn bring about novel opportunities to enhance food protection research, although this technology may not be suitable for wide-scale domestic food safety education of consumers because ownership of VR headsets is not commonplace. Nevertheless, given the affordability and portability of VR headsets, this technology could be used as an educational tool to facilitate training in the food manufacturing industry. VR technology can replicate a real environment, which is beneficial when the representative environment is not easily accessible or when delivery of training could be an inconvenience for people working in that area. For example, one-to-one training on procedures in high-risk or highcare food manufacturing environments could be delivered using VR technology. Because variables are controlled, this ensures the reliability and repeatability of the training and can allow comparison of awareness between participants or changes in awareness of participants over time. VR technology has been used to present trainees with scenarios designed to teach important lessons with the goal of meeting Food Safety Modernization Act standards. The data obtained with VR technology can be used to plan future training sessions according to identified areas of difficulty among trainees (86).

VR-based training could be superior to classroombased training because of the feelings of immersion and presence, which can trigger an emotional response (9, 84) and thus aid in learning and memory (101). The use of VR environments in health and safety training has had better outcomes for changing attitudes and awareness than those achieved with PowerPoint-based training methods (60). The Corrupt Kitchen VR environment was designed to explore attitudes toward workplace corruption. However, the design, development, and creation of the VR environment was very detailed and lengthy (103-106). The potential usability, impact, effectiveness, and acceptability of VR-based food safety training in food industry environments need further study.

\section{AR technology}

Augmented reality (AR) is often confused with VR because both technologies are computer generated. Unlike VR technology (an interactive computer-generated experience taking place within a simulated environment), AR technology superimposes a computer-generated image on the user's view of the real world (25). This approach allows people to add digital information to their physical world without having to immerse themselves into a virtual replacement of an actual environment. Thus, users of $A R$ technology can interact in real time with computer-generated objects within their actual physical environment (3). AR technology is widely used in smartphone applications. For example, computer-generated filters and effects can be applied over real-life images on social media platforms (Instagram, Snapchat, Facebook, etc.), enabling users to give visual expressions (79).

\section{AR application for food safety education and training}

Popular smartphone-based AR games such as Pokémon Go (a GPS location-based AR game) are unique because they combine the physical and virtual world in one interface, which encourages exercise, socialization, and outdoor activity (89). AR is often used to give an interactive experience in museums $(54,73)$. In addition to use with smartphones, $A R$ technology can be experienced with AR wearables such as smart glasses (80), which have been utilized in construction and high-end manufacturing (67).

AR technology also can enhance digital shopping experiences and sales $(32,33)$. Consumers can download AR smartphone applications that enable the prepurchase visualization of products by placing virtual content (e.g., new furniture) in a real environment (e.g., image of the consumer's home) (83), which has a positive impact on consumers and e-commerce vendors $(12,49)$. AR technologies have also been applied in health care environments (98) as cognitive aids for people in the early stages of memory loss (50) and as tools to improve competencies, learning, or critical thinking in health care education by providing an authentic and engaging experience $(18,126)$. Application of AR technology in education could be used to engage, stimulate, and motivate students, to help teach subjects for which real-world firsthand experience is not feasible, and to create an authentic learning environment suitable to various learning styles (125). However, successful design, development, and application of $\mathrm{AR}$ educational technology requires a framework driven by learning theory (127).

Games and activities are commonly used in consumer food safety educational campaigns, particularly those targeted at children $(40,74,88)$. Given the widespread ownership of smartphones, consumer food safety campaigns using AR technology may be an alternative approach for food safety educators. Beck et al. (6) discussed the potential application of AR in the food industry to enhance the training of new employees and suggested that AR could enable employees to locate supplies or identify objects and could provide a technological alternative to the presence of a mentor. Ryznar (87) suggested that AR technology could transform food service and food production facilities by improving speed, quality, efficiency, consistency, traceability, and training. In food manufacturing environments, AR technology could be used to visualize and understand the importance of cleaning and how pathogens grow in such environments and how bacterial niches are established. 


\section{STE technology}

Unlike the AR and VR technologies, which use a headmounted display, smartphone, tablet, or computer to view the virtual or augmented scenes of an environment, simulated task environment (STE) technology utilizes a video theatre design. The video theatre comprises high-resolution flat panel displays (capable of higher resolution than typical consumergrade televisions) or rear projection media panels to recreate a computer-synthesized depiction of an environment in which the viewer occupies the space within the video theatre (24, 62) (Fig. 1). Sensors communicate user movement and interaction within the video theatre and maintain appropriate real-time rendering of environment scales during exploration. STE setup often includes allied props and multisensory cues to increase presence and context (65). Because the real environment can be too complex to provide experimental control, variables in an STE can be controlled, potentially making it easier to study behavior in an STE than in the actual task environment (45). Consequently, researchers can study behavior in a task environment that is appropriate to the research question of interest $(45,75)$.

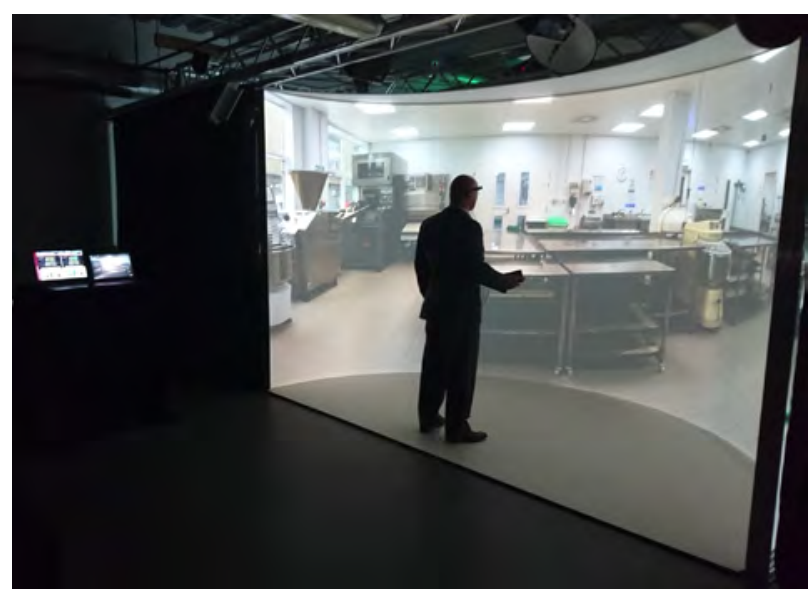

FIGURE 1. Example of STE technology at the Perceptual Experience Laboratory (Cardiff Metropolitan University). The research facility comprises of a 2.5-m-tall high-resolution cylindrical rear-projection screen that wraps $200^{\circ}$ around the participant. The screen can be configured to represent virtually any environment in terms of sight, sound, smell, temperature, air movement, and physical objects (117).

\section{STE application for food safety training}

Global companies are using STE and VR technologies to better understand consumer purchasing behaviors (53), to improve the design of products and packaging, and thus strengthen brand competitiveness. The use of STEs to test packaging designs concurs with Young's (123) opinion that product testing is more valid when participants are in an appropriate shopping context with realistic product surroundings. Inclusion of multisensory cues in an STE (e.g., olfactory cues, temperature control, air movement, auditory effects, and props) facilitates presence and engagement (65) and has successfully provided real-life context for product testing across several research areas $(42,43,58,59)$. Given the technical setup and running costs for STE facilities, this technology is used exclusively for in-house testing by companies with large research, development, and marketing budgets. Consequently, dissemination of commercial research activity and such valuable insights are not available in the public domain, and small and medium-size businesses may not have access to such valuable technology.

STEs could be used to expand upon the training and education capabilities of AR and VR by delivering interactive group training relating to areas that are not easily accessible and enabling peer-to-peer learning. Knowledge-based training alone may not improve food safety performance, whereas behavior-based training approaches are often more effective for improving food safety performance and frequency (124). The use of simulated tasks in an STE facility may provide a knowledge and behavioral training approach to enhancing food safety.

\section{Eye tracking}

Eye-tracking technologies project near-infrared light onto an individual's eyes, producing reflections that are captured by sensors and then processed by algorithms that infer gaze points (where the user is looking), allowing metric calculations of eye movement data (108). Eye-tracking data can be captured with either wearable eye-tracking technology (e.g., eye-tracking glasses (115)) or unobtrusive screen-based eye-tracking technology (e.g., eye-tracking bar placed on a laptop (114) or a laptop webcam (113)).

Eye tracking provides noninvasive and comprehensive data on brain function and cognition (30). Eye-tracking technology allows the assessment of an individual's visual attention and behavior while performing tasks within a desired setting. Eye-tracking data are initially observed using attention-based heat maps and gaze path visualization. Detailed investigations rely on demarcating areas of interest for quantitative analysis (111). These unique insights have resulted in widespread use of eye-tracking technology throughout the research, development, and marketing stages for new and existing products from global manufacturing companies (107).

The ability to capture an unbiased visual record of a participant's subconscious during tasks (implicit research) robustly supports behavioral and attention insights and removes the uncertainty (lack of candor) associated with response data collected with traditional research methods such as questionnaires, in which responses can be subject to biases $(110,112)$. Eye-tracking technology has significantly improved in its usability, accuracy, and speed while decreasing in cost (28), resulting in increased availability and use in research $(82,107)$. Research exploring visual reaction to stimuli has been conducted in psychology, 
neuroscience, education, health, medicine, linguistics, reading, ophthalmology, visual perception, software development, and user experience $(82,109)$.

\section{Eye-tracking application in food safety research}

Within food and drink settings, fixations and saccades (rapid movements) are analyzed to examine shopper engagement with packaging, which can be used to improve in-store merchandising (116, 120-122). Pieters and Warlop (77) determined product preference correlated with shopper attention. Although eye-tracking technology is widely used to explore consumer behavior, it also could be applied to explore the interaction of a target audience with food safety educational interventions such as videos or leaflets. This technology could be particularly beneficial for evaluation of interventions to determine engagement or specific points of disengagement and to determine whether all critical elements were being "seen." The data captured with such technology could inform placement of key messages in interventions. Eye-tracking technology can be used alongside STE and head-mounted displays to explore visualizations in an immersive environment. Lawrence et al. $(58,59)$ explored how commercial STE and eye-tracking research is conducted for food packaging design assessment, providing real-life context for product testing in a laboratory setting. Research combining VR and eye-tracking technology can be used to assess decision making in real-life scenarios (69), particularly in hazardous situations $(91,102)$.

\section{Biometric technologies}

Numerous biometric technologies are available to provide physiological measurements via sensors that monitor specific bodily activity (e.g., pulse rate, brain activity, sweat glands, visible expressions, and pupil diameter) as indicators of human responses and reactions to experiences.

- Emotion state software: Facial expression coding software recognizes facial muscle activity to provide measurements of emotions through visible expressions (61). Emotion state technology is a noncontact automated system founded on the basic emotion states defined by Ekman and Friesen (31) (happiness, sadness, anger, surprise, disgust, and fear). The technology has been used by researchers and marketers interested in understanding the effect of stimuli on emotions and human behavior through evaluation of the effects of emotions on mood. The nonverbal communication of emotions provides objective insights into the interactions of individuals with other people, machines, and products (97). In food-mood research, this biometric technique can be used to detect changes in emotion states evoked by various food tastes. Traditionally, consumer acceptance of new food products is tested explicitly (e.g., acceptance ratings). Implicit tests of emotion states can provide additional information on consumer acceptance and enjoyment of foods (27).

- Galvanic skin response technology: With this technology, the conductivity of skin (electrodermal activity) can be assessed via sensors attached to the fingers; these sensors then measure changes in the skin conductance response $(10,11,14)$. The differences in the electrical conduciveness of the skin is caused by changes in moisture levels (sweat) (23), which are associated with mental activity. This technology can be used to determine physiological arousal, which is used as an indicator of emotional response to stimuli $(10,55)$, and is regarded as one of the most robust measurements of arousal (38). Galvanic skin response data have been used to measure the psychological state of participants in wide-ranging research scenarios that encompass emotionally evocative stimuli (55), anticipations of risks (21), consumer attitudes, and purchasing behavior $(19,46,47,72,119)$.

- Heart rate variability technology: The electrical activity of the heart, as measured with an electrocardiogram, can vary during the cardiac cycle $(1,90,94)$. Advances in portable sport and health devices (e.g., the Fitbit) in recent years has increased the accessibility of heart rate data and can indicate levels of physiological arousal away from the laboratory (7). During stress, the heart rate increases due to processes in the autonomic nervous system $(2,26,76,96)$. Variations in heart rate can also indicate immediate changes in arousal, physical effort, cognitive effort, and attention $(8,78,99)$. In research settings, prolonged cardiac deceleration has been associated with enhanced attention and processing of stimuli $(13,57)$. The effectiveness of advertising stimuli can be highly dependent on arousal and attention capabilities $(8,57)$. This biometric approach has been applied in STE-based tourism research to assess reactions to a tourism-related setting and to explore the potential for tourism to alleviate stress and enhance hedonic well-being $(4,63,92,93)$.

\section{Biometric technology application in food safety research}

In consumer research, biometric measurements (heart rate, galvanic skin response, and emotion state) have been combined to investigate responses to popular and unpopular brand logos (66). Although each technology has its individual merit, combining such technologies is beneficial for obtaining a robust interpretation of physiological arousal and emotional intensity in response to stimuli. The multimodal approach of combining biometric techniques can strengthen behavior predictors (118). Combined biometric techniques could be used to measure a variety of emotional responses to food safety training or education interventions. Emotion is an important element in education because it 
drives attention, learning, and memory (101). For food safety training, education, and messaging, targeting the emotional side of food handlers may be more successful than formal training (68). Triggering an emotional response in food safety risk communication may shape risk perceptions and motivate people toward behavior changes. An understanding of the emotions associated with food safety risk communication is an important tool for motivating people to change their behavior (39). An emotional response can be instrumental in shaping an individual's food safety risk perception and in motivating their adoption of preventive practices (70). Consequently, the emotions triggered by food safety training or educational interventions should be identified. Future studies could be conducted to assess the physiological and psychological impacts in addition to the cognitive and behavioral impacts of food safety interventions.

\section{CONCLUSIONS}

This article provides information on some of the novel technologies that have become increasingly available and accessible to researchers in recent years but have not been fully utilized in the area of food protection. Opportunities for exciting transdisciplinary research have been proposed that could open research fields that cannot be fully subsumed within a single specialization and may offer the most relevant approach to developing solutions to problems in the real world (39). Technologies such as VR and AR will become valuable allies in the quest for improved product, worker, and customer safety in the food industry (71). Technologies such as VR, AR, STE, eye tracking, and biometric measurements of emotion state, galvanic skin response, and heart rate variability can be utilized to provide exiting and innovative opportunities for exploring and enhancing food safety training, education interventions, and research opportunities. These technologies could be combined to provide an indepth understanding and evaluation of the engagement and interaction of consumers and food handlers with food safety training and education interventions. The novel technologies described here could be triangulated with existing cognitive and behavioral food safety research methods to produce a holistic approach. Such important discoveries could be utilized to transform current approaches to design, develop, implement, and evaluate food safety interventions and thus improve our research, training, and education capabilities for enhancing food protection.

\section{REFERENCES}

1. Acharya, U. R., K. P. Joseph, N. Kannathal, C. M. Lim, and J. S. Suri. 2006. Heart rate variability: a review. Med. Biol. Eng. Comput. 44:1031-1051.

2. Akselrod, S., D. Gordon, F. A. Ubel, D. C. Shannon, A. C. Berger, and R. J. Cohen. 1981. Power spectrum analysis of heart rate fluctuation: a quantitative probe of beat-to-beat cardiovascular control. Science 213:220-222.

3. Azuma, R. T. 1997. A survey of augmented reality. Presence Teleoper. Virtual Environ. $6: 355-385$

4. Baldwin, J., C. Haven-Tang, S. Gill, N. Morgan, and A. Pritchard. 2020. Using the Perceptual Experience Laboratory (PEL) to simulate tourism environments for hedonic wellbeing. Inf. Technol. Tourism. https://doi. org/10.1007/s40558-020-00179-x.

5. Barfield, W., D. Zeltzer, T. Sheridan, and M. Slater. 1995. Presence and performance within virtual environments, p. 473-513. In virtual environments and advanced interface design. Oxford University Press, Oxford.

6. Beck, D., P. Crandall, C. O’Bryan, and J. Shabatura. 2016. Taking food safety to the next level-an augmented reality solution. J. Foodserv. Bus. Res. 19:1-14.

7. Birenboim, A., and N. Shoval. 2016. Mobility research in the age of the smartphone. Ann. Am. Assoc. Geogr. 106:283-291.

8. Bolls, P. D., D. D. Muehling, and K. Yoon. 2003. The effects of television commercial pacing on viewers' attention and memory. J. Mark. Commun. 9:17-28.
9. Bosse, T., C. Gerritsen, J. de Man, and J. Treur. 2013. Effects of virtual training on emotional response, p. 21-32. In K. Imamura, S. Usui, T. Shirao, T. Kasamatsu, L. Schwabe, and N. Zhong (ed.), Brain and health informatics. BHI 2013. Lecture notes in computer science 8211 . Springer International, Cham, Switzerland.

10. Boucsein, W. 2012. Electrodermal activity, 2nd ed. Springer, New York.

11. Boucsein, W., D. C. Fowles, S. Grimnes, G. Ben-Shakhar, W. T. Roth, M. E. Dawson, and D. L. Filion. 2012. Publication recommendations for electrodermal measurements. Psychophysiology 49:1017-1034.

12. Boyajian, L. 2017. The real cost of returns for retailers. Retail Next. Available at: https:// retailnext.net/en/blog/the-real-cost-of-returns-for-retailers/. Accessed 27 May 2020.

13. Bradley, M. M. 2009. Natural selective attention: orienting and emotion. Psychophysiology 46:1-11

14. Braithwaite, J. J., D. G. Watson, R. Jones, and M. Rowe. 2013. A guide for analysing electro dermal activity (EDA) \& skin conductance responses (SCRs) for psychological experiments. Psychophysiology 49:1017-1034.

15. Bruder, G., and D. Valkov. 2010. Augmented virtual studio for architectural exploration. Presented at the 12th Virtual Reality International Conference, Laval, France, 7 to 9 April 2010.

16. Brusilovski, P., P. Kommers, and N. Streitz (ed.). 1996. Multimedia, hypermedia, and virtual reality: models, systems, and application. First international conference, MHVR'94, Moscow, Russia, September (1416), 1996. Selected papers. Lecture notes in computer science 1077. Springer, Berlin.

17. Card, S. K., G. G. Robertson, and J. D. Mackinlay. 1991. The information visualizer, an information workspace, p. 181-186. In SIGCHI conference on human factors in computing systems. Association for Computing Machinery, New Orleans, LA.

18. Carlson, K. J., and D. J. Gagnon. 2016. Augmented reality integrated simulation education in health care. Clin. Simul. Nurs. 12:123-127.

19. Caruelle, D., A. Gustafsson, P. Shams, and L. Lervik-Olsen. 2019. The use of electrodermal activity (EDA) measurement to understand consumer emotions-a literature review and a call for action. J. Bus. Res. 104:146-160.

20. Chapman, B., T. MacLaurin, and D. Powell. 2013. Video observation and data coding methods to assess food handling practices at food service. Food Prot. Trends 33:146-156.

21. Critchley, H. D., C. J. Mathias, and R. J. Dolan. 2001. Neural activity in the human brain relating to uncertainty and arousal during anticipation. Neuron 29:537-545.

22. Darken, R. P., D. Bernatovich, J. P. Lawson, and B. Peterson. 1999. Quantitative measures of presence in virtual environments: the roles of attention and spatial comprehension. Cyberpsychol. Behav. 2:337-347. 
23. Dawson, M. E., A. M. Schell, and D. L. Filion. 2017. The electrodermal system, chap. 10. In J. Cacioppo, L. Tassinary, and G. Berntson (ed.), Handbook of psychophysiology. Cambridge University Press, Cambridge.

24. DeFanti, T. A., D. J. Sandin, and C. Cruz-Neira. 1993. A "room" with a "view." IEEE Spectrum 30:30-33.

25. Deshpande, V., and J. Sanghavi. 2019. Augmented reality: technology merging computer vision and image processing by experimental techniques. Int. J. Innov. Technol. Explor. Eng. 8:534-537.

26. De Vente, W., M. Olff, J. G. C. Van Amsterdam, J. H. Kamphuis, and P. M. G. Emmelkamp. 2003. Physiological differences between burnout patients and healthy controls: blood pressure, heart rate, and cortisol responses. Occup. Environ. Med. 60:i54.

27. De Wijk, R. A., D. Kaneko, G. B. Dijksterhuis, M. van Zoggel, I. Schiona, M. Visalli, and E. H. Zandstra. 2019. Food perception and emotion measured over time in-lab and inhome. Food Qual. Pref. 75:170-178.

28. Duchowski, A. T. 2017. Eye tracking methodology: theory and practice. Springer, New York.

29. Earnshaw, R. A. 2014. Virtual reality systems. Elsevier, New York.

30. Eckstein, M. K., B. Guerra-Carrillo, A. T. Miller Singley, and S. A. Bunge. 2017. Beyond eye gaze: what else can eyetracking reveal about cognition and cognitive development? Dev. Cogn. Neurosci. 25:69-91.

31. Ekman, P., and W. V. Friesen. 1971. Constants across cultures in the face and emotion. J. Persp. Soc. Psychol. 17:124-129.

32. Engine Creative Agency, Ltd. 2020. Argos augmented reality powered shopping app. Available at: https://www.enginecreative. co.uk/portfolio/argos-augmented-reality-powered-shopping-app/. Accessed 28 April 2020.

33. Engine Creative Agency, Ltd. 2020. VADO augmented reality product visualiser app for iOS and android. Available at: https:// www.enginecreative.co.uk/portfolio/ vado-augmented-reality-product-visualiser-app-for-ios-and-android/\#. Accessed 28 April 2020.

34. Evans, E. W., and E. C. Redmond. 2014. Behavioral risk factors associated with listeriosis in the home: a review of consumer food safety studies. J. Food Prot. 77:510-521.

35. Evans, E. W., and E. C. Redmond. 2018. Behavioral observation and microbiological analysis of older adult consumers' cross-contamination practices in a model domestic kitchen. J. Food Prot. 81:569-581.

36. Evans, E. W., and E. C. Redmond. 2018. Video observation of hand-hygiene compliance in a manufacturer of ready-to-eat pie and pastry products. Int. J. Environ. Health Res. 29:593-606.
37. Evans, E. W., E. J. Samuel, and E. C. Redmond. 2020. A case study of food handler hand hygiene compliance in high-care and high-risk food manufacturing environments using covert-observation. Int. J. Environ. Health Res. https://doi.org/ 10.1080/09603123.2020.1791317.

38. Figner, B., and R. Murphy. 2011. Using skin conductance in judgment and decision making research, chap. 7. In M. Schulte-Mecklenbeck, A. Kühberger, and R. Ranyard (ed.), A handbook of process tracing methods for decision research: a critical review and user's guide. Psychology Press, London.

39. Fischer, A. R. H., A. E. I. De Jong, R. De Jonge, L. J. Frewer, and M. J. Nauta. 2005. Improving food safety in the domestic environment: the need for a transdisciplinary approach. Risk Anal. 25:503-517.

40. Food Standards Agency. 2019. Food hygiene resources for school children in Wales. Available at: https://www.food.gov.uk/print/pdf/ node/1551. Accessed 28 April 2020.

41. Gibson, E. J., J. J. Gibson, O. W. Smith, and H. Flock. 1959. Motion parallax as a determinant of perceived depth. J. Exp. Psychol. 58:40-51.

42. Gordon, B. 2010. Emulation of a real life environment via an augmented virtual environment. M.Sc. dissertation. Swansea Metropolitan University, Swansea, Wales. Available at: https://repository.cardiffmet. ac.uk/bitstream/handle/ 10369/906/EmulationRealLife_BG.pdf?sequence $=1 \&$ isAllowed=y. Accessed 16 April 2020.

43. Gordon, B., G. Loudon, and S. Gill. 2019. Product user testing: the void between laboratory testing and field testing. Presented at International Association of Societies of Design Research Conference, Manchester, UK, September 2019. Available at: https://www. researchgate.net/publication/337362984 Product_user_testing_the_void_between Laboratory testing and Field testing. Accessed 7 May 2020

44. Gordon, J. S., and R. McNew. 2008. Developing the online survey. Nurs. Clin. N. Am. 43:605-619.

45. Gray, W. 2002. Simulated task environments. Cogn. Sci. Q. 2:205-227.

46. Groeppel-Klein, A. 2005. Arousal and consumer in-store behavior. Brain Res. Bull. 67:428-437.

47. Guerreiro, J., P. Rita, and D. Trigueiros. 2015. Attention, emotions and cause-related marketing effectiveness. Eur. J. Mark. 49:1728-1750.

48. Gurwitsch, A. 2010. Maurice Merleau-Ponty, phénoménologie de la perception (Paris: Librairie Gallimard, 1945), p. 487-490. In J. García-Gómez (ed.), The collected works of Aron Gurwitsch (1901-1973), vol. I. Constitutive phenomenology in historical perspective. Springer, Dordrecht, Netherlands.
49. Hartjen, R. 2017. Augmented reality and how it changes online shopping. Retail Next. Available at: https://retailnext.net/en/blog/ augmented-reality-and-how-it-changes-online-shopping-infographic/. Accessed 16 April 2020.

50. Hayhurst, J. 2018. How augmented reality and virtual reality is being used to support people living with dementia-design challenges and future directions, p. 295-305. In T. Jung and M. C. tom Dieck (ed.), Augmented reality and virtual reality: empowering human, place and business. Springer International, Cham, Switzerland.

51. Heilig, M. L. October 1960. Stereoscopic-television apparatus for individual use. U.S. patent 2955156A.

52. Heilig, M. L. August 1962. Sensorama simulator. U.S. patent 3050870A.

53. Hughes, N. 2010. Visions of the future: Unilever's customer insight \& innovation centre. Available at: https://www.thegrocer. co.uk/companies/visions-of-the-future-unilevers-customer-insight-and-innovation-centre/210661.article. Accessed 7 May 2020.

54. Koterwas, T., J. Suess, S. Billings, A. Haith, and A. Lamb. 2018. Augmenting reality in museums with interactive virtual models, $\mathrm{p}$. 365-370. In T. Jung and M. C. tom Dieck (ed.), Augmented reality and virtual reality: empowering human, place and business Springer International, Cham, Switzerland.

55. Kreibig, S. D. 2010. Autonomic nervous system activity in emotion: a review. Biol. Psychol. 84:394-421.

56. Krishen, K. (ed.). 1992. Fifth annual workshop on space operations applications and research (SOAR '91). National Aeronautics and Space Administration, Washington, D.C.

57. Lang, A. 1990. Involuntary attention and physiological arousal evoked by structural features and emotional content in tv commercials. J. Commun. Res. 17:275-299.

58. Lawrence, A., G. Loudon, S. Gill, and J. Baldwin. 2019. Simulated environments for food packaging design assessment. Presented at the 11th international conference on culinary arts and sciences, Cardiff, UK, June 2019.

59. Lawrence, A., G. Loudon, S. Gill, R. Pepperell, and J. Baldwin. 2019. Geometry vs realism: an exploration of visual immersion in a synthetic reality space. Presented at the International Associations of Societies in Design Research Conference, Manchester, UK, 2 to 5 September 2019. Available at: https:// repository.cardiffmet.ac.uk/bitstream/ handle/10369/10716/Geometry\%20vs\%20 Realism-\%20an\%20exploration\%20of\%20 visual\%20immersion\%20in\%20a\%20synthetic\%20reality $\% 20$ space $\% 20 \% 281 \% 29$. pdf ?sequence $=1$ \&isAllowed $=y$. Accessed 16 April 2020. 
60. Lawson, G., E. Shaw, T. Roper, T. Nilsson, L. Bajorunaite, and A. Batool. 2019. Immersive virtual worlds: multi-sensory virtual environments for health and safety training. Institution of Occupational Safety and Health research report. Available at: https://www. iosh.com/multisensoryVE. Accessed 16 April 2020 .

61. Loijens, L., and O. Krips. 2019. FaceReader methodology. A white paper by Noldus Information Technology. Available at: https:// www.noldus.com/files/file_manager/ downloads/whitepaper/FaceReader_Methodology.pdf. Accessed 16 April 2020.

62. Loomis, J. M., J. J. Blascovich, and A. C. Beall. 1999. Immersive virtual environment technology as a basic research tool in psychology. Behav. Res. Methods Instrum. Comput. 31:557-564.

63. Marchiori, E., E. Niforatos, and L. Preto. 2018. Analysis of users' heart rate data and self-reported perceptions to understand effective virtual reality characteristics. Inf. Technol. Tourism 18:133-155.

64. Marsh, T., P. Wright, and S. Smith. 2001. Evaluation for the design of experience in virtual environments: modeling breakdown of interaction and illusion. Cyberpsychol. Behav. 4:225-238.

65. Martins, J., R. Gonçalves, F. Branco, L. Barbosa, M. Melo, and M. Bessa. 2017. A multisensory virtual experience model for thematic tourism: a port wine tourism application proposal. J. Destin. Mark. Manag. 6:103-109.

66. Maxian, W., S. D. Bradley, W. Wise, and E. N. Toulouse. 2013. Brand love is in the heart: physiological responding to advertised brands. Psychol. Mark. 30:469-478.

67. McDonnell, M. 2018. The augmented worker. p. 371-378. In T. Jung, and M.C. tom Dieck (ed.), Augmented reality and virtual reality: Empowering human, place and business Springer International Publishing, Cham.

68. McFarland, P., A. C. Sielaff, B. Rasco, and S. Smith. 2019. Efficacy of food safety training in commercial food service. J. Food Sci. 84:1239-1246.

69. Meißner, M., J. Pfeiffer, T. Pfeiffer, and H. Oppewal. 2019. Combining virtual reality and mobile eye tracking to provide a naturalistic experimental environment for shopper research. J. Bus. Res. 100:445-458.

70. Mou, Y., and C. A. Lin. 2014. Communicating food safety via the social media: the role of knowledge and emotions on risk perception and prevention. Sci. Commun. 36:593-616.

71. Nichols, M. R. 2019. How will AR and VR improve safety in the food industry? Available at: https://foodsafetytech.com/column/ how-will-ar-and-vr-improve-safety-in-thefood-industry/. Accessed 28 April 2020.

72. Ohira, H., and N. Hirao. 2015. Analysis of skin conductance response during evaluation of preferences for cosmetic products. Front. Psychol. 6.
73. Padilla-Meléndez, A., and A. R. del Águila-Obra. 2013. Web and social media usage by museums: online value creation. Int. J. Inf. Manag. 33:892-898.

74. Partnership for Food Safety Education. 2020. Kids games \& activities. Available at: https://www.fightbac.org/kidsfoodsafety/ kids-games-and-activities/. Accessed 28 April 2020 .

75. Patton, D. 2014. How real is good enough? Assessing realism of presence in simulations and its effects on decision making, $\mathrm{p}$. 245-256. In D. D. Schmorrow and C. M. Fidopiastis (ed.), Foundations of augmented cognition: advancing human performance and decision-making through adaptive systems. Springer International, Cham, Switzerland.

76. Pieper, S., J. F. Brosschot, R. van der Leeden, and J. F. Thayer. 2007. Cardiac effects of momentary assessed worry episodes and stressful events. Psychosom. Med. 69:901-909.

77. Pieters, R., and L. Warlop. 1999. Visual attention during brand choice: the impact of time pressure and task motivation. Int. J. Mark. Res. 16:1-16.

78. Poels, K., and S. Dewitte. 2006. How to capture the heart? Reviewing 20 years of emotion measurement in advertising. J. Advert. Res. 46:18-37.

79. Poulsen, S. V. 2018. Constructing the corporate Instagram discourse-a critical visual discourse approach. Digit. Age Semiot. Commun. 1:95-112.

80. Rauschnabel, P. A. 2018. A conceptual uses \& gratification framework on the use of augmented reality smart glasses, p. 211-227. In T. Jung and M. C. tom Dieck (ed.), Augmented reality and virtual reality: empowering human, place and business. Springer International, Cham, Switzerland.

81. Redmond, E., C. Griffith, J. Slader, and T. Humphrey. 2004. Microbiological and observational analysis of cross-contamination risks during domestic food preparation. Br. Food J. 106:581-597.

82. Reingold, E. M. 2014. Eye tracking research and technology: towards objective measurement of data quality. Vis. Cogn. 22:635-652.

83. Rese, A., D. Baier, A. Geyer-Schulz, and S. Schreiber. 2017. How augmented reality apps are accepted by consumers: a comparative analysis using scales and opinions. Technol. Forecast. Soc. Change 124:306-319.

84. Riva, G., F. Mantovani, C. S. Capideville, A. Preziosa, F. Morganti, D. Villani, A. Gaggioli, C. Botella, and M. Alcañiz. 2007. Affective interactions using virtual reality: the link between presence and emotions. Cyberpsychol. Behav. 10:45-56.

85. Robertson, G. G., S. K. Card, and J. D. Mackinlay. 1993. Information visualization using $3 \mathrm{D}$ interactive animation. Commun. ACM 36:57-71.
86. RTI International. 2020. Impact: modernizing food safety through immersive video training. Available at: https://www. rti.org/impact/modernizing-food-safety-through-immersive-video-training. Accessed 16 April 2020.

87. Ryznar, P. 2018. A new (augmented) reality Food safety tech. Available at: https://foodsafetytech.com/feature_article/a-new-augmented-reality/. Accessed 17 April 2020.

88. SafeFood, Environmental Health Service, and Food Standards Agency of Northern Ireland. n.d. Beat the bingo bug. The original food safety game. Available at: http://www. safefood.eu/SafeFood/media/SafeFoodLibrary/Documents/Publications/Consumer/ BingoCards.pdf. Accessed 16 April 2020.

89. Serino, M., K. Cordrey, L. McLaughlin, and R. L. Milanaik. 2016. Pokémon Go and augmented virtual reality games: a cautionary commentary for parents and pediatricians. Curr. Opin. Pediatr. 28:673-677.

90. Shaffer, F., R. McCraty, and C. L. Zerr. 2014. A healthy heart is not a metronome: an integrative review of the heart's anatomy and heart rate variability. Front. Psychol. 5. https://doi.org/10.3389/fpsyg.2014.01040.

91. Shaw, E., T. Roper, T. Nilsson, G. Lawson, S. V. G. Cobb, and D. Miller. 2019. The heat is on: exploring user behaviour in a multisensory virtual environment for fire evacuation, paper 626. In Proceedings of the 2019 CHI Conference on Human Factors in Computing Systems. Association for Computing Machinery, Glasgow, Scotland.

92. Shoval, N., Y. Schvimer, and M. Tamir. 2017. Real-time measurement of tourists' objective and subjective emotions in time and space. J. Travel Res. 57:3-16.

93. Shoval, N., Y. Schvimer, and M. Tamir. 2018. Tracking technologies and urban analysis: adding the emotional dimension. Cities 72:34-42.

94. Sinnreich, R., J. D. Kark, Y. Friedlander, D. Sapoznikov, and M. H. Luria. 1998. Five minute recordings of heart rate variability for population studies: repeatability and age-sex characteristics. Heart 80:156-162.

95. Slater, M., and S. Wilbur. 1997. A framework for immersive virtual environments Five: speculations on the role of presence in virtual environments. Presence Teleoper. Virtual Environ. 6:603-616.

96. Steptoe, A. 2000. Stress, social support and cardiovascular activity over the working day. Int. J. Psychophysiol. 37:299-308.

97. Stockli, S., M. Schulte-Mecklenbeck, S. Borer, and A. C. Samson. 2018. Facial expression analysis with AFFDEX and FACET: a validation study. Behav. Res. Methods 50:1446-1460.

98. Stone, R. J. 2018. Blending the best of the real with the best of the virtual: mixed reality case studies in healthcare and defence, $p$. 277-293. In T. Jung and M. C. tom Dieck (ed.), Augmented reality and virtual reality: empowering human, place and business. Springer International, Cham, Switzerland. 
99. Sung, B., N. Hartley, E. Vanman, and I. Phau. 2016. How can the word "new" evoke consumers' experiences of novelty and interest? J. Retail Consum. Serv. 31:166-173.

100. Sutherland, I. E. 1968. A head-mounted three dimensional display, p. 757-764. In Proceedings of the December 9-11, 1968, fall joint computer conference. Part I. Association for Computing Machinery, San Francisco.

101. Sylwester, R. 1994. How emotions affect learning. Educ. Leaders 52:60-65.

102. Szulewski, A., and D. Howes. 2014. Combining first-person video and gaze-tracking in medical simulation: a technical feasibility study. Sci. World J. https://doi.org/ $10.1155 / 2014 / 975752$.

103. Tennent, P., and S. Moran. 2017. The corrupt kitchen VR. Digital research blogs, University of Nottingham, Nottingham, UK.

104. Tennent, P., and S. Moran. 2017. Corrupt kitchen VR dev-diary 2. Digital research blogs, University of Nottingham, Nottingham, UK.

105. Tennent, P., and S. Moran. 2017. Developing the corrupt kitchen VR. Digital research blogs, University of Nottingham, Nottingham, UK.

106. Tennent, P., and S. Moran. 2018. Corrupt kitchen VR dev-diary 3. Digital research blogs, University of Nottingham, Nottingham, UK.

107. Tobii Pro. 2020. About us. Our customers. Available at: https://www.tobiipro.com/ about/customers/. Accessed 22 March 2020.

108. Tobii Pro. 2020. What is eye tracking? Available at: https://tech.tobii.com/technology/what-is-eye-tracking/. Accessed 22 March 2020.

109. Tobii Pro. 2020. Eye tracking research paper reference library. Available at: https://www. tobiipro.com/research-paper-referencelibrary/. Accessed 23 March 2020.
110. Tobii Pro. 2020. Improve workplace safety with eye tracking. Available at: https:// www.tobiipro.com/blog/improve-workplace-safety-with-eye-tracking/. Accessed 26 May 2020.

111. Tobii Pro. 2020. Marketing and consumer research. Available at: https://www.tobiipro. com/ fields-of-use/marketing-consumer-research/. Accessed 23 March 2020.

112. Tobii Pro. 2020. Psychology and neuroscience. Available at: https://www.tobiipro. com/ fields-of-use/psychology-and-neuroscience/. Accessed 26 May 2020.

113. Tobii Pro. 2020. Sticky by Tobii Pro. Available at: https://www.tobiipro.com/product-listing/sticky-by-tobii-pro/. Accessed 26 May 2020

114. Tobii Pro. 2020. Tobii Pro fusion. Available at: https://www.tobiipro.com/product-listing/fusion/. Accessed 23 March 2020.

115. Tobii Pro. 2020. Tobii Pro glasses 2. Available at: https://www.tobiipro.com/ product-listing/tobii-pro-glasses-2/?creative $=411561111560 \&$ keyword $=$ tobii $\% 20$ glasses\&matchtype $=\mathrm{e} \&$ network $=\mathrm{g} \& \mathrm{de}-$ vice $=c \& g c l i d=C j w K C A j w \_L L 2 B R A k E i-$ wAv2Y3Sd-IWCXz-1cXPdAK9kRMXMbi0z0adV8oAxIlsvP 7y4G3j7rNzLg3 RoCsFoQAvD_BwE. Accessed 23 March 2020.

116. Tonkin, C., A. Ouzts, and A. Duchowski. 2011. Eye tracking within the packaging design workflow: interaction with physical and virtual shelves. First conference on novel gaze-controlled applications, Karlskrona, Sweden, 26 to 27 May 2011. Available at: https://dl.acm.org/ doi/10.1145/1983302.1983305. Accessed 23 March 2020.

117. User Centred Design Research Group. n.d. Perceptual experience laboratory. Available at: https://ucdresearch.com/the-perceptual-experience-laboratory/. Accessed 27 May 2020.
118. Venkatraman, V., A. Dimoka, P. A. Pavlou, K. Vo, W. Hampton, B. Bollinger, H. E. Hershfield, M. Ishihara, and R. S. Winer. 2015. Predicting advertising success beyond traditional measures: new insights from neurophysiological methods and market response modeling. J. Mark. Res. 52:436-452.

119. Vila-Lopez, N., and I. Kuster-Boluda. 2019. Consumers' physiological and verbal responses towards product packages: could these responses anticipate product choices? Physiol Behav. 200:166-173.

120. Wedel, M. 2015. Attention research in marketing: a review of eye-tracking studies, p. 569-588. In J. Fawcett, E. Risko, and A. Kingstone (ed.), The handbook of attention. MIT Press, Cambridge, MA.

121. Wedel, M., and R. Pieters. 2006. Eye tracking for visual marketing. Found. Trends Mark. 1:231-320.

122. Wedel, M., and R. Pieters. 2008. A review of eye-tracking research in marketing, $\mathrm{p}$. 123-147. In K. M. Naresh (ed.), Review of marketing research, vol. 4. Emerald Group, Bingley, UK.

123. Young, S. 2002. Packaging design, consumer research, and business strategy: the march toward accountability. Design Manag. J. 13(4):10-14.

124. Yu, H., J. Neal, M. Dawson, and J. M. Madera. 2017. Implementation of behavior-based training can improve food service employees' handwashing frequencies, duration, and effectiveness. Cornell Hosp. Q. 59:70-77.

125. Yuen, S. C.-Y., G. Yaoyuneyong, and E. Johnson. 2011. Augmented reality: an overview and five directions for AR in education. J. Educ. Technol. Dev. Exch. 4:119-140.

126. Zhu, E., A. Hadadgar, I. Masiello, and N Zary. 2014. Augmented reality in healthcare education: an integrative review. Peer] 2:e469.

127. Zhu, E., A. Lilienthal, L. Shluzas, I. Masiello, and N. Zary. 2015. Design of mobile augmented reality in health care education: a theory-driven framework. JMIR Med. Educ. $1:$ e10. 